\title{
Artesunate exerts protective effects against ulcerative colitis via suppressing Toll-like receptor 4 and its downstream nuclear factor- $\kappa B$ signaling pathways
}

\author{
YU-XUAN CHEN, XIAO-QI ZHANG, CHENG-GONG YU, SHU-LING HUANG, \\ YING XIE, XIAO-TAN DOU, WEN-JIA LIU and XIAO-PING ZOU
}

Department of Gastroenterology, Nanjing Drum Tower Hospital, Nanjing University, Nanjing, Jiangsu 210000, P.R. China

Received July 30, 2018; Accepted November 28, 2018

DOI: $10.3892 / \mathrm{mmr} .2019 .10345$

\begin{abstract}
Artesunate (ART) is a semi-synthetic derivative of artemisinin used in the treatment of patients with malaria, which has also been reported to have immunoregulatory, anticancer and anti-inflammatory properties. The aim of the present study was to investigate the possible beneficial effects of ART on ulcerative colitis (UC) rats and to detect the possible mechanisms underlying these effects. A UC rat model was established using dextran sulfate sodium (DSS). Rats were randomly divided into the following groups: Normal control, UC model group, UC rats treated with a low, medium or high dose of ART (10, 30 and $50 \mathrm{mg} / \mathrm{kg} / \mathrm{day}$, respectively), and the positive control group $(50 \mathrm{mg} / \mathrm{kg} / \mathrm{day} 5$-aminosalicylic acid). The damage status of colonic mucosal epithelial tissue was investigated by hematoxylin and eosin staining, and then the weight, colon length and disease activity index (DAI) were measured. Western blotting and reverse transcription-quantitative polymerase chain reaction analysis were used to detect the levels of cytokines associated with UC and proteins associated with Toll-like receptor 4 (TLR4)-nuclear factor (NF)- $\mathrm{B}$ pathway. ELISA was also performed to measure the levels of inflammatory cytokines. In addition, the viability and infiltration of RAW264.7 cells were examined using Cell Counting Kit- 8 and Transwell assays. The results demonstrated that treatment with ART significantly alleviated the UC symptoms induced by DSS in the rat model, lowered the DAI, ameliorated pathological changes, attenuated colon shortening, inhibited the levels of pro-inflammatory mediators and myeloperoxidase activity, and increased hemoglobin expression. Additionally, inflammatory and apoptotic markers were found to be significantly downregulated following treatment
\end{abstract}

Correspondence to: Dr Xiao-Ping Zou, Department of Gastroenterology, Nanjing Drum Tower Hospital, Nanjing University, 321 Zhongshan Road, Nanjing, Jiangsu 210000, P.R. China

E-mail: zhouxp005@163.com

Key words: ulcerative colitis, artesunate, Toll-like receptor 4, nuclear factor- $\kappa \mathrm{B}$, anti-inflammatory with ART in UC rats and RAW264.7 cells. To the best of our knowledge, the present study is the first to demonstrate that ART exerts anti-inflammatory effects via regulating the TLR4-NF- $\kappa B$ signaling pathway in UC.

\section{Introduction}

Ulcerative colitis (UC) is an idiopathic, chronic inflammatory colitis that manifests as diffuse mucosal inflammation of the colon and rectum, and interferes with intestinal motility; however, and the exact pathogenesis of UC remains poorly understood. UC mainly includes rectal and proximal transmission, and does not affect the digestive tract beyond the ileocecal valve. In recent years, the numbers of individuals suffering from UC has been continuously increasing in several countries (1). UC most commonly affects individuals aged between 30 and 40 years $(2,3)$. The pathogenesis of UC is multifactorial, including immune responses disorders, genetic susceptibility, epithelial barrier defects and adverse environmental factors, among others (4). Treatments for UC include aminosalicylates for mild-to-moderate disease, topical and systemic steroids for disease outbreaks, and immunosuppressants and biopharmaceuticals for moderate-to-severe disease, whereas patients with refractory disease or colonic tumors require colectomy (4). However, the effective management of UC represents a major challenge.

Artemisinin was isolated from the Artemisia (genus) plant in 1971 and is a medicinal natural product commonly used in the treatment of malaria (5). Recent studies have demonstrated that artemisinin derivatives also exert anti-tumor effects (6-10), which have attracted attention for use as anticancer drugs. Due to its anti-inflammatory properties, artesunate (ART), a semi-synthetic derivative of artemisinin, has been used in the treatment of a variety of inflammatory diseases. It has also been reported that ART can inhibit the activation of the Toll-like receptor 4 (TLR4)-nuclear factor (NF)- $\mathrm{kB}$ pathway (11). However, the effect of ART on UC remains unknown. Therefore, the aim of the present study was to evaluate the anti-inflammatory effects of ART on DSS-induced UC.

Tumor necrosis factor (TNF)- $\alpha$ and interleukins (ILs) serve crucial roles in the inflammatory process of UC. Accumulating evidence suggests that the TNF- $\alpha$ gene regulates the development 
of UC, and increased levels of TNF- $\alpha$ have been detected in patients with UC; thus, TNF- $\alpha$ is a pro-inflammatory mediator with a key role in the pathogenesis of inflammatory bowel diseases (12). In addition, pro-inflammatory ILs serve an important role in the pathogenesis of UC, and high IL levels secreted by macrophages have been associated with the severity of inflammation in colitis (13). Nuclear factor (NF)- $\kappa$ B p65 is an important transcription factor that regulates a large number of genes involved in immune and inflammatory responses. NF- $\mathrm{BB}$ is a key transcription factor of M1 macrophages and induces a number of inflammatory genes, including TNF- $\alpha$, IL-1 $\beta$, IL-6, IL-10, IL-12, and cyclooxygenase-2 $(14,15)$. Inactivated NF- $\mathrm{NB}$ is potentially involved in pro-apoptotic signaling pathways (16). Furthermore, $\mathrm{NF}-\kappa \mathrm{B}$ increases B-cell lymphoma 2 (Bcl-2) expression, resulting in a decrease in cellular apoptosis (17). Previous studies have demonstrated that NF- $\mathrm{KB}$ signaling dysfunction is closely associated with the pathogenesis and progression of UC $(18,19)$. Since the $\mathrm{NF}-\kappa \mathrm{B}$ signaling pathway is widely known to be involved in inflammatory response $(20,21)$, its inactivation may be critical for the effective therapy of UC (22).

Another hallmark of UC, namely inflammation limited to the mucosa, may be associated with TLR4 (23). In mice exposed to DSS, treatment with anti-TLR4 antibodies resulted in the attenuation of inflammation of the colon, and downregulated the expression levels of IL- $1 \beta$, TNF- $\alpha$ and interferon (IFN) $-\gamma$ (24). It is well known that the TLR4-NF- $\kappa$ B signaling pathway is a commonly recognized inflammatory pathway, which is likely to be activated in DSS-induced UC. These findings prompted the investigation of the effects of ART on UC.

The aim of the present study was to investigate whether ART attenuated the DSS-induced colon injury and to further elucidate whether the underlying mechanism involves regulating the TLR4-NF- $\mathrm{B}$ signaling pathway, in order to assess the potential of ART as an effective intervention for UC treatment.

\section{Materials and methods}

Materials. ART (SA9720) was purchased from Solarbio Life Sciences (Beijing, China). TRIzol Reagent (cat. no. 15596026; Thermo Fisher Scientific, Inc.) was used to extract the total RNA. The 2X Taq PCR Master Mix was obtained from Beijing Baiao Laibo Technology Co., Ltd. (Beijing, China). Western blot analysis, hematoxylin and eosin (H\&E) staining, cell RIPA lysis buffer solution was purchased from Beyotime Institute of Biotechnology and ELISA assay kits were purchased from Abcam and R\&D Systems China Co., Ltd. The TLR4, NF-кB p65, phosphorylated (p)-p38, Bcl-2, Bcl-2-associated $\mathrm{X}$ protein (Bax) and caspase- 9 primary antibodies, and the horseradish peroxidase-conjugated goat anti-rabbit/mouse secondary antibodies were obtained from Abcam or Cell Signaling Technology, Inc. Lipopolysaccharide (LPS; from Escherichia coli 0111:B4; L2630) and DSS (D4911) powder were purchased from Sigma-Aldrich (Merck KGaA, Darmstadt, Germany). The compound 5-aminosalicylic acid (5-ASA) was purchased from Tokyo Kasei Kogyo Co., Ltd.

Animals. Male Sprague-Dawley rats weighing 200-250 g (7 weeks old; $n=48$ ) were used in the experiments, which were purchased from Nanjing Qinglongshan Experimental
Animal Breeding Farm. The rats were housed in a specific-pathogen-free environment, and kept under an automated 12-h light/dark cycle at a controlled temperature of $24 \pm 2^{\circ} \mathrm{C}$ and relative humidity of $50-60 \%$, with ad libitum access to food and tap water. All animals received humane care and the experimental procedures were conducted in strict accordance with the Guide to the Care and Use of Experimental Animals. All experimental procedures performed on the rats were approved by the Animal Experiment Ethics Committee of Nanjing Drum Tower Hospital (Nanjing, China).

Animal grouping. All animals were randomly divided into the following six groups, according to different treatments: Normal control group (CG), DSS-induced UC model group (DG), low-dose ART group (LG), middle-dose ART group (MG), high-dose ART group (HG) and positive control drug group (PG). Rats in each group had diets with the same energy density, macronutrient composition and trace elements.

UC animal model. DSS-induced colitis in rats was induced as described previously (25). Briefly, DSS was added to drinking water to a final concentration of $3 \%$. The DSS solution was freshly prepared and replaced daily. Rats were randomly divided into six groups (normal control, UC model, positive control and three ART-treated groups), with 8 rats per group. Rats in the control group were given normal drinking water, while drinking water containing $3 \%$ DSS was given to the model, positive control and three ART-treated groups. After 10 days of DSS administration, the drinking water of all the rats was replaced with normal drinking water on the day 11 . The rats were given free access to water during the experiment. On day 11 after DSS induction, the three experimental groups were orally administered different doses of ART (10, 30 and $50 \mathrm{mg} / \mathrm{kg} /$ day) for 5 days, while the positive control drug group was orally administered 5-ASA (50 mg/ $\mathrm{kg} /$ day) in $1 \mathrm{ml} 0.9 \%$ $\mathrm{NaCl}$ saline. Rats in the normal control and model groups were orally administered $1 \mathrm{ml} / \mathrm{kg}$ /day of $0.9 \%$ phosphate-buffered saline (PBS). Subsequent to the last dose, the rats were fasted for $24 \mathrm{~h}$, and on the following day, rats from each group were randomly selected for the follow-up experiments.

Measurement of disease activity index (DAI). The symptoms of colonic inflammation in all rats were monitored daily. The stool viscosity rating criteria were as follows: A rating of 0 indicated normal stool, a rating of 2 indicated thin stool, while a rating of 4 points indicated diarrhea. Bloody stool was also rated as follows: 0 indicated normal stool, a rating of 2 indicated fecal occult blood-positive, and 4 indicated bleeding. The weight loss rating criteria were as follows: 0 , no change; 1 , weight loss of $1-5 \%$ of the initial body weight; 2 , weight loss of $5-10 \%$ of the initial body weight; 3 , weight loss of $10-15 \%$ of the initial body weight; and 4 , weight loss of $>15 \%$ of the initial body weight. Finally, the DAI was measured as previously described (26). The DAI score was calculated as the sum of scores assigned for weight loss, stool consistency and rectal bleeding.

Histological analysis of the colon and changes in colon length. After the rats were euthanized, the colons were immediately resected. Next, the mesenteric tissue, blood vessels and fat were carefully removed, and the colon length was measured. 
Subsequent to washing the intestine with PBS, a $\sim 4 \mathrm{~cm}$ segment of the distal colon was removed and weighed. For histological examination, 1-cm segments from the distal colon were fixed in $10 \%$ formalin, embedded in paraffin, cut into 5-mm sections and placed on the slides. In order to observe the histological changes, colon sections were stained with H\&E and then examined under an Olympus microscope (Olympus Corporation, Tokyo, Japan). The histological score of the H\&E-stained colon specimens was evaluated in terms of the degrees of lymphocyte infiltration, mucosal erosion, colonic crypt damage and ulcer formation. Histological scoring was performed in a blinded manner, according to the classic scoring system described by Cooper et al (27). The rest of the colon tissue was immediately frozen in liquid nitrogen and then stored at $-80^{\circ} \mathrm{C}$ for subsequent western blot and reverse transcription-quantitative polymerase chain reaction (RT-qPCR) analyses.

Measurement of myeloperoxidase (MPO) in colon tissue. Colon tissue $(1 \mathrm{~g})$ was mashed with a mortar and pestle in $1 \mathrm{ml}$ of $20 \mathrm{mM}$ potassium phosphate buffer ( $\mathrm{pH} \mathrm{7.0)}$. The supernatants were collected by centrifugation at $16,000 \mathrm{x} \mathrm{g}$ for $10 \mathrm{~min}$ at $4^{\circ} \mathrm{C}$, and the level of MPO was measured using assay kits purchased from Abcam (Cambridge, MA, USA; cat. no. ab43321).

Cell culture and treatment. RAW264.7 cells were purchased from the American Type Culture Collection (Manassas, VA, USA) and cultured in Dulbecco's modified Eagle's medium (DMEM) containing 10\% (v/v) fetal bovine serum (FBS; Gibco; Thermo Fisher Scientific, Inc.) at $37^{\circ} \mathrm{C}$ in a humidified atmosphere with $5 \% \mathrm{CO}_{2}$ and $95 \%$ air, until 70-80\% confluence was reached (28). The cells $\left(2 \times 10^{5}\right.$ cells/well $)$ were then seeded into 24-well plates and incubated for $24 \mathrm{~h}$. Subsequently, RAW264.7 cells were stimulated with LPS ( $1 \mu \mathrm{g} / \mathrm{ml}$; Gibco; Thermo Fisher Scientific, Inc.) for $48 \mathrm{~h}$, followed by treatment with different concentration of ART $(5,10$ and $20 \mu \mathrm{g} / \mathrm{ml})$ or with 5-ASA ( $20 \mathrm{mmol} / \mathrm{l})$, which was used as a positive control. After $24 \mathrm{~h}$, the cells were collected for use in further experiments. The experimental grouping of cells was as follows: Control, LPS, 5-ASA, ART 5, ART 10 and ART 20 groups.

Measurement of cytopathological state. RAW264.7 cells were fixed with $4 \%$ paraformaldehyde for 15 min and washed with distilled water for $2 \mathrm{~min}$, followed by two 2-min washes with distilled water. The processed samples were stained with hematoxylin for $10 \mathrm{~min}$ and then rinsed with distilled water for $10 \mathrm{~min}$ to remove any excess stain. Next, the samples were washed for $5 \mathrm{sec}$ with $95 \%$ ethanol and then with distilled water. Finally, the samples were stained with eosin solution for $1 \mathrm{~min}$, washed twice with $70 \%$ ethanol and directly observed under an Olympus microscope. The affected cells exhibited an increased cell size, unclear cell borders or cell structure disruptions, and histological scoring was determined based on the number of abnormal cells and according to the classic scoring system of Cooper et al (27).

Measurement of cell migration by a Transwell assay. The cell migration ability was assayed using 24-transwell inserts with $8-\mu \mathrm{m}$ microporous membranes. Briefly, cell suspensions ( $2 \times 10^{5}$ cells/well) were added to the upper chamber of a transwell migration system (BD Biosciences, Franklin Lakes, NJ, USA) and incubated for $12 \mathrm{~h}$ at $37^{\circ} \mathrm{C}$. Following starving for $8 \mathrm{~h}$ in FBS-free DMEM to eliminate the influence of serum, $500 \mu 1$ DMEM high-glucose medium supplemented with 10\% FBS (Thermo Fisher Scientific, Inc.) was added into the lower Transwell chamber. Then, the indicated treatments were added and the cells were allowed to migrate for $24 \mathrm{~h}$. Non-migrating cells were removed from the upper surface of the insert with a cotton swab. Migrating cells were fixed with $100 \%$ ethanol for $20 \mathrm{~min}$, followed by staining with crystal violet solution. Images of the migrating cells were captured using an Olympus microscope.

Measurement of inflammatory factor levels by ELISA. After the last administration, the rats were fasted for $24 \mathrm{~h}$ and blood samples were collected the next day. The serum sample $(0.5 \mathrm{ml})$ was obtained from the tail veins of rats, and the serum was isolated by centrifugation at $500 \mathrm{x} \mathrm{g}$ for $5 \mathrm{~min}$. The rat $\mathrm{Hb}$ kit (cat. no. ml0187371; Shanghai Enzyme-linked Biotechnology Co., Ltd.) was used to measure the $\mathrm{Hb}$ content in rat serum. RAW264.7 cells $\left(2 \times 10^{5}\right.$ cells/well) were plated into 96-well plates and cultured overnight at $37^{\circ} \mathrm{C}$. Subsequently to the indicated treatments, culture supernatants of RAW264.7 cells were collected to detect the levels of inflammatory factor. The concentrations of IL-8 (cat. no. CK-E30583; R\&D Systems China Co., Ltd., Shanghai, China), IFN- $\gamma$ (cat. no. ab46107; Abcam) and TNF- $\alpha$ (cat. no. ab46105, Abcam) were measured using their respective ELISA kits, according to the protocols recommended by the manufacturer. The inflammatory factor levels were measured in both the rat serum samples and RAW264.7 cells.

Measurement of cell viability. The viability of RAW264.7 cells was assessed using the Cell Counting Kit-8 (CCK-8) assay. Cells $\left(5 \times 10^{3}\right.$ cells/well) were seeded on a 96 -well plate. Following the indicated cell treatments, CCK-8 reagent was added to the culture medium, and the cells were cultured for $1 \mathrm{~h}$ at $37^{\circ} \mathrm{C}$ in a humidified atmosphere with $95 \%$ air and $5 \%$ $\mathrm{CO}_{2}$. Absorbance was measured at $490 \mathrm{~nm}$ using a microplate reader (Bio-Rad Laboratories, Inc., Hercules, CA, USA).

$R T-q P C R$. Total RNA was extracted from colon tissues and RAW264.7 cells using TRIzol reagent (Invitrogen; Thermo Fisher Scientific, Inc.) and treated with DNase I (Promega Corporation, Madison, WI, USA). The RNA purity and concentration were measured using an UV spectrophotometer and RT was then performed using T7-(dT) ${ }_{24}$ oligo primers and the Custom SuperScript Double-Stranded cDNA Synthesis kit (Invitrogen; Thermo Fisher Scientific, Inc.) following the instructions of the manufacturer. The reverse transcription conditions were $10 \mathrm{~min}$ at $25^{\circ} \mathrm{C}, 30 \mathrm{~min}$ at $48^{\circ} \mathrm{C}$, and a final step of $5 \mathrm{~min}$ at $95^{\circ} \mathrm{C}$. The cDNA samples were stored at $-20^{\circ} \mathrm{C}$ for subsequent qPCR analysis. Next, qPCR for the evaluation of mRNA levels was performed by PowerUp SYBR Green Master Mix (Thermo Fischer Scientific) according to the manufacturer's protocol. The qPCR reactions $(20 \mu \mathrm{l})$ were performed as follows: $2 \mathrm{~min}$ at $95^{\circ} \mathrm{C}$, followed by 40 cycles of $15 \mathrm{sec}$ at $95^{\circ} \mathrm{C}$ and $60 \mathrm{sec}$ at $60^{\circ} \mathrm{C}$. qPCR primers used are listed in Table I. The fold relative expression was calculated according to the $2^{-\Delta \Delta \mathrm{Cq}}$ method (29) and normalized to GAPDH. Three repeated experiments were performed for each qPCR reaction. 
Table I. Primers used in quantitative polymerase chain reaction analysis.

\begin{tabular}{lll}
\hline Gene & \multicolumn{1}{c}{ Forward primer (5'-3') } & \multicolumn{1}{c}{ Reverse primer (5'-3') } \\
\hline TLR4 & AAATGCACTGAGCTTTAGTGGT & TGGCACTCATAATGATGGCAC \\
NF- - B & AGGCTTCTGGGCCTTATGTG & TGCTTCTCTCGCCAGGAATAC \\
TNF- $\alpha$ & CCCTCACACTCAGATCATCTTCT & GCTACGACGTGGGCTACAG \\
p38 & GGGACACCCCCTGCTTATCT & TCCCTGCTTTCAAAGGACTGG \\
IFN- $\gamma$ & ACAGCAAGGCGAAAAAGGATG & TGGTGGACCACTCGGATGA \\
IL-8 & TCGAGACCATTTACTGCAACAG & CATTGCCGGTGGAAATCCTT \\
Bax & AGACAGGGGCCTTTTTGCTAC & AATTCGCCGGAGACACTCG \\
BcL-2 & GCTACCGTCGTGACTTCGC & CCCCACCGAACTCAAAGAAGG \\
Caspase-9 & AGCCAGAGGTTCTCAGACCAG & ATATCTGCATGTCCCCTGATCT \\
GAPDH & TGACCTCAACTACATGGTCTACA & CTTCCCATTCTCGGCCTTG
\end{tabular}

TLR4, Toll-like receptor 4; NF- $\kappa \mathrm{B}$, nuclear factor- $\kappa \mathrm{B}$; TNF- $\alpha$, tumor necrosis factor- $\alpha$; IFN- $\gamma$, interferon- $\gamma$; IL, interleukin; Bcl-2, B-cell lymphoma 2; GAPDH, glyceraldehyde 3-phosphate dehydrogenase.

Western blot analysis. Total proteins were extracted from the rat colon tissue and RAW264.7 cells using a protein isolation kit (Beyotime Institute of Biotechnology), and the protein concentration was measured using a bicinchoninic assay kit (Beyotime Institute of Biotechnology). The protein samples were separated by sodium dodecyl sulfate polyacrylamide gel electrophoresis (8-12\%), and the protein bands were then transferred onto PVDF membranes. Following blocking in $5 \%$ skim milk for $2 \mathrm{~h}$ at room temperature, the membranes were incubated at $4^{\circ} \mathrm{C}$ overnight with the designated primary antibodies against TLR4 (cat. no. ab13556; 1:500), NF- $\mathrm{BB}$ p65 (cat. no. ab16502; 1:1,000), TNF- $\alpha$ (cat. no. ab6671; 1:1,000), Bax (cat. no. ab199677; 1:1,000), Bcl-2 (cat. no. ab196495; 1:1,000), Caspase-9 (cat. no. ab25758; 1:1,000) and GAPDH (cat. no. ab37168; 1:10,000), which were purchased from Abcam, and with anti-p-p38 (cat. no. 4511S; 1:1,000) that was purchased from Cell Signaling Technology (Danvers, MA, USA). Subsequently, the blots were labeled with horseradish peroxidase-conjugated goat anti-rabbit IgG H\&L (cat. no. ab6721; 1:10,000; Abcam). Then, the membranes were developed with ECL (Beyotime Institute of Biotechnology). Signals were quantified using ImageJ software (version 1.47; National Institutes of Health, Bethesda, MD, USA).

Statistical analysis. All data are presented as the mean \pm standard derivation. Statistical analyses were performed with SPSS software, version 17.0 (SPSS, Inc., Chicago, IL, USA). Statistical differences among groups were determined by one-way analysis of variance followed by Dunnett's post hoc test, and the quantitative variables were compared using the paired Student's- $t$ test. $\mathrm{P}<0.05$ was considered to indicate a statistically significant difference.

\section{Results}

Effect of ART on DAI in UC rats. The DAI in the CG remained unchanged until day 14 , whereas the DAI in the DG increased gradually with increasing DSS treatment time between days 0 and 10 (Fig. 1A). After 10 days, there was a significant difference in DAI between CG and DG $(\mathrm{P}<0.001$; Fig. 1A). However, treatment of UC model rats with ART inhibited the increase in DAI in a dose-dependent manner when compared with that in untreated model rats. On day 14, the difference in DAI between the DG and all the treatment groups (LG, MG, HG and PG) was statistically significant (LG vs. DG, $\mathrm{P}<0.01$; MG vs. DG, $\mathrm{P}<0.01$; HG vs. DG, $\mathrm{P}<0.001$; $\mathrm{PG}$ vs. DG, $\mathrm{P}<0.001$; Fig. $1 \mathrm{~A})$.

Effect of ART on the serum hemoglobin $(\mathrm{Hb})$ content of $U C$ rats. ELISA revealed that DSS treatment significantly reduced the blood $\mathrm{Hb}$ level as compared with that in healthy animals in the $\mathrm{CG}(\mathrm{P}<0.001$; Fig. 1B). However, ART treatment in the model animals increased the blood $\mathrm{Hb}$ level in a dose-dependent manner. The difference in $\mathrm{Hb}$ content between the DG and the treatment groups $\mathrm{MG}, \mathrm{HG}$ and $\mathrm{PG}$ was statistically significant (MG vs. DG, $\mathrm{P}<0.05$; HG vs. DG, $\mathrm{P}<0.01$; $\mathrm{PG}$ vs. $\mathrm{DG}, \mathrm{P}<0.001$; Fig. 1B), whereas no marked difference was observed between the DG and LG levels.

Effect of ART on DSS-induced colon length reduction in UC rats. As shown in Fig. 2A and B, DSS treatment caused a significant decrease in the colon length of the UC model rats, as compared with that in control rats $(\mathrm{P}<0.001)$. Treatment with ART prevented the DSS-induced colon length reduction in UC model rats, with statistically significant differences observed between the DG and the treatment groups MG, HG and PG (MG vs. DG, P<0.05; HG vs. DG, P<0.001; PG vs. DG, $\mathrm{P}<0.001$; Fig. 2A and B).

Effect of ART on the activity of MPO in UC rats. DSS treatment increased oxidative stress in UC rats by markedly increasing the levels of MPO, as compared with those observed in healthy animals in the $\mathrm{CG}(\mathrm{P}<0.001$; Fig. $2 \mathrm{C})$. Comparatively, ART improved the antioxidant capacities of UC rats by reducing the activity of MPO in a dose-dependent manner, with significant differences detected between the DG and the other treatment groups (LG vs. DG, P<0.01; MG vs. DG, $\mathrm{P}<0.001$; HG vs. DG, $\mathrm{P}<0.001 ; \mathrm{PG}$ vs. DG, $\mathrm{P}<0.001$; Fig. $2 \mathrm{C}$ ).

Protective effect of ART against DSS-induced colon damage. To determine the pathological changes in the colon, 
A

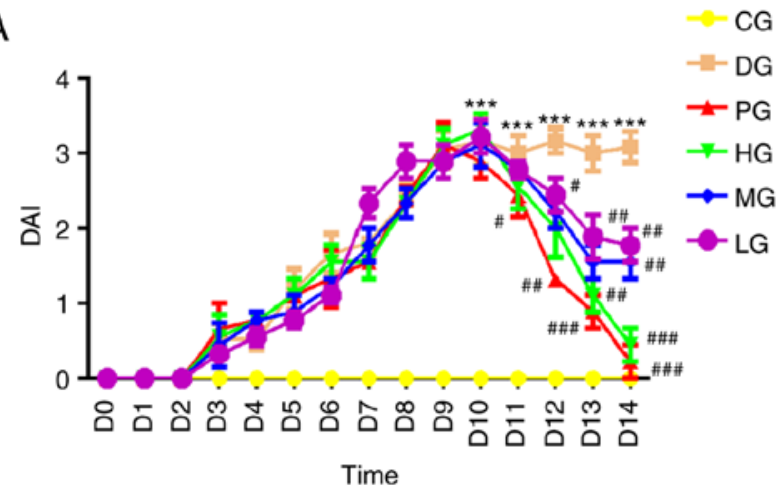

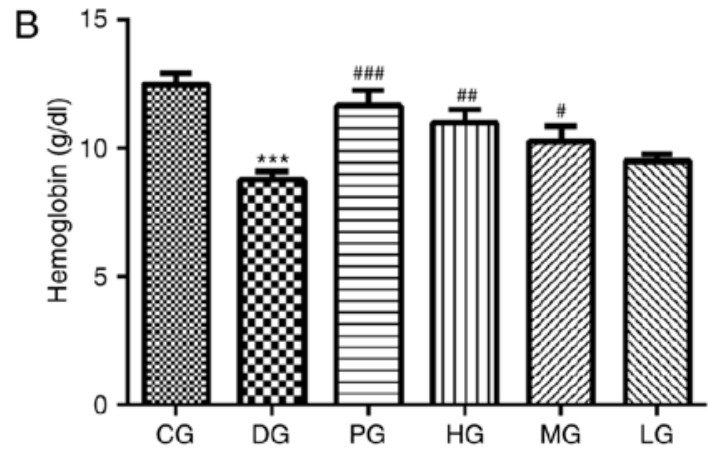

Figure 1. Effects of ART on (A) DAI and (B) hemoglobin in a rat ulcerative colitis model. ${ }^{* * *} \mathrm{P}<0.001$ vs. CG; ${ }^{\#} \mathrm{P}<0.05,{ }^{\# \#} \mathrm{P}<0.01$ and ${ }^{\# \# \#} \mathrm{P}<0.001$, vs. DG. ART, artesunate; DAI, disease activity index; CG, control group; DG, dextran sulfate sodium-treated model group; LG, low-dose ART group; MG, middle-dose ART group; HG, high-dose ART group; PG, positive control group.
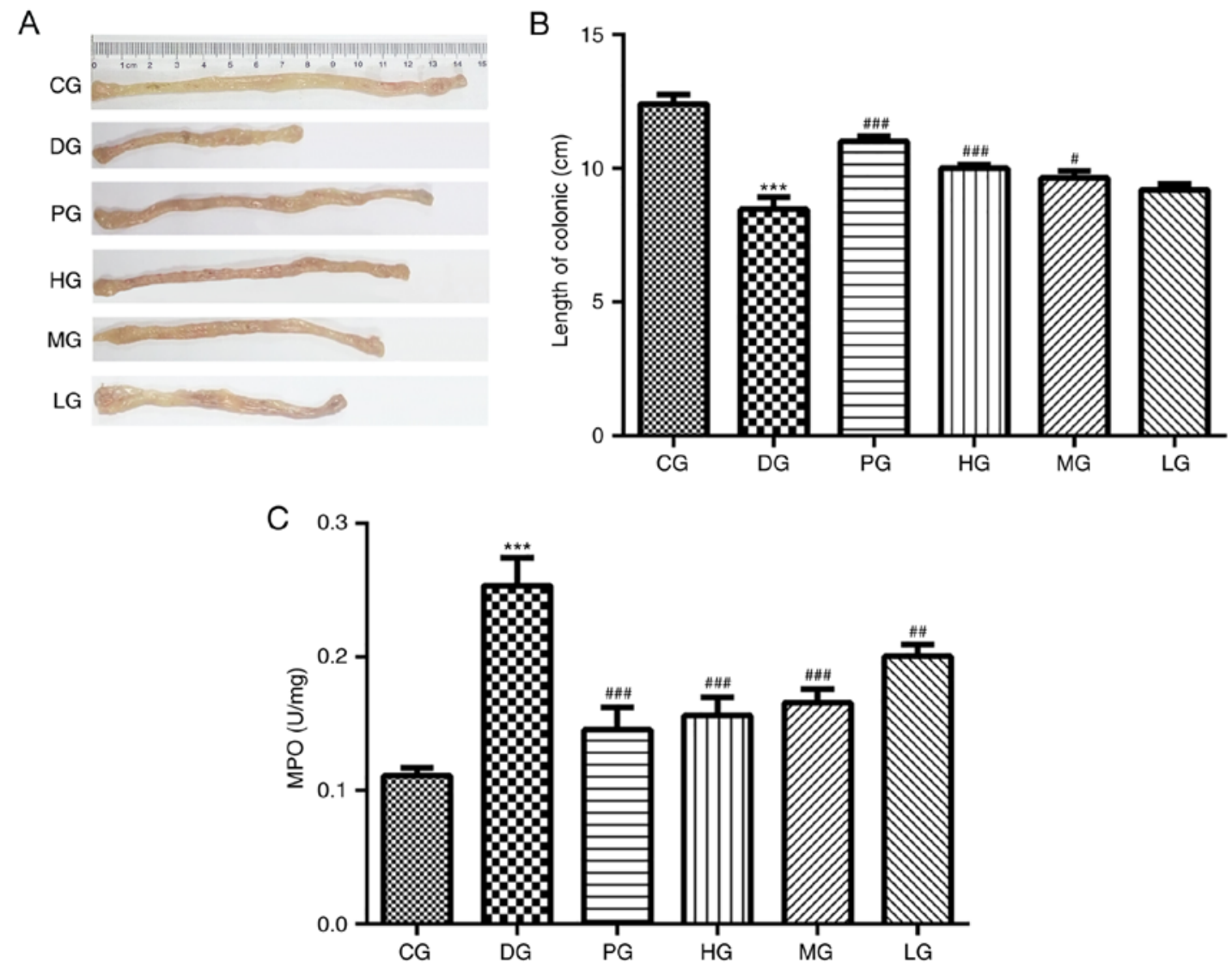

Figure 2. Effects of ART on colon length and MPO in a rat UC model. (A) Representative images of colon sections from rats in each group. (B) Quantification of the change in colon length in each group. (C) Change in the activity of MPO in UC rats in each group. ${ }^{* * *} \mathrm{P}<0.001$ vs. $\mathrm{CG}$; ${ }^{\#} \mathrm{P}<0.05$, ${ }^{\# \#} \mathrm{P}<0.01$ and

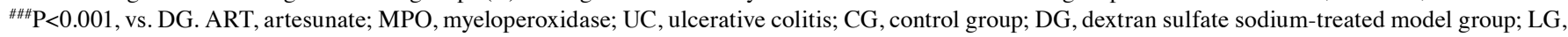
low-dose ART group; MG, middle-dose ART group; HG, high-dose ART group; PG, positive control group.

H\&E staining was performed. Histological examination revealed a normal tissue structure, as well as appearance of the cell nuclei and cytoplasm, in the CG (Fig. 3A). DSS treatment caused tissue damage with cell destruction, whereas ART treatment in UC rats reduced the severity of the damage in a dose-dependent manner. In terms of the histological scores, the differences between the DG and the treatment groups $\mathrm{MG}, \mathrm{HG}$ and $\mathrm{PG}$ were statistically significant (MG vs. DG, $\mathrm{P}<0.05$; HG vs. DG, $\mathrm{P}<0.01$; PG vs. DG, $\mathrm{P}<0.01$; Fig. 3B).
Effects of ART on the serum levels of inflammatory factors in $U C$ rats. ELISA demonstrated that DSS treatment increased the serum levels of the inflammatory factors TNF- $\alpha$, IL-8 and IFN- $\gamma$ when compared with those in healthy animals in the $\mathrm{CG}(\mathrm{P}<0.001$; Fig. 4). By contrast, ART administration in UC rats inhibited the increase in the serum levels of TNF- $\alpha$, IL- 8 and IFN- $\gamma$ in a dose-dependent manner, with statistically significant differences detected between the DG and the treatment groups MG, HG and PG (MG vs. DG, $\mathrm{P}<0.05$; HG vs. DG, $\mathrm{P}<0.01$; $\mathrm{PG}$ vs. DG, $\mathrm{P}<0.01$; Fig. 4), 
A

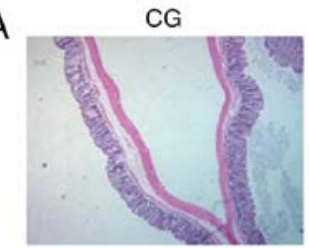

HG

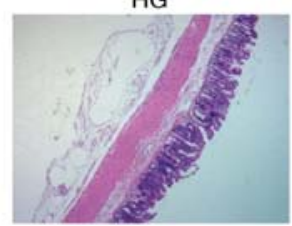

DG

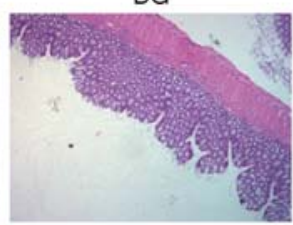

MG

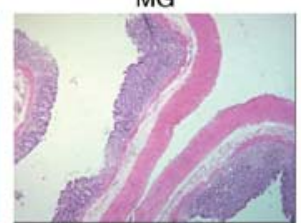

PG

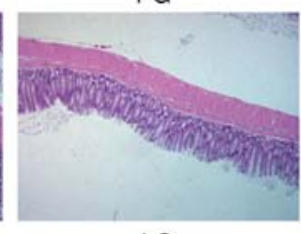

LG

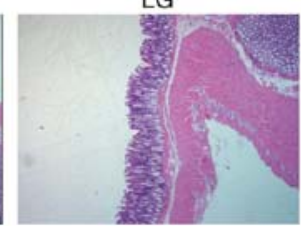

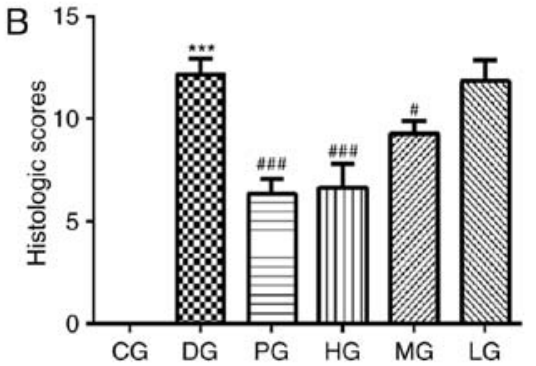

Figure 3. Effects of ART on the pathological alterations in the colon. (A) Representative images of hematoxylin and eosin stained sections (magnification, $\mathrm{x} 200$ ), and (B) quantification of the pathological alterations in the colon according to the histological score. ${ }^{* * *} \mathrm{P}<0.001 \mathrm{vs}$. CG; ${ }^{\#} \mathrm{P}<0.05$ and ${ }^{\# \# \#} \mathrm{P}<0.001, \mathrm{vs}$. $\mathrm{DG}$. ART, artesunate; CG, control group; DG, dextran sulfate sodium-treated model group; LG, low-dose ART group; MG, middle-dose ART group; HG, high-dose ART group; PG, positive control group.

whereas no differences were observed between the DG and LG levels.

Effects of ART on the regulation of key molecules involved in the TLR4-NF- $\kappa B$ signaling pathway in UC rats. As shown in Fig. 5A, compared with the CG, DSS treatment increased the protein levels of TLR4, p-NF- $\mathrm{kB}, \mathrm{p}-\mathrm{p} 38$, Bax and caspase-9, whereas it reduced the protein level of Bcl-2. Treatment of UC model rats with ART inhibited the activity of the TLR4-NF- $\mathrm{KB}$ signaling pathway by reducing the expression levels of TLR4, $\mathrm{p}-\mathrm{NF}-\kappa \mathrm{B}, \mathrm{p}-\mathrm{p} 38$, Bax and caspase-9, and increasing the expression of Bcl-2 in a dose-dependent manner. The difference in the expression was statistically significant between DG and the treatment groups MG, HG and PG (all $\mathrm{P}<0.01$ or $\mathrm{P}<0.001$; Fig. 5A). Notably, these levels were not significantly altered in the LG compared with DG, while the protein levels of NF- $\mathrm{kB}$ and p38 did not differ markedly among all groups. Comparatively, the results of RT-qPCR on the mRNA levels of TLR4, p-NF- $\kappa$ B, p-p38, Bax, caspase-9 and Bcl-2 were consistent with the results of western blotting (Fig. 5B). Furthermore, the results of RT-qPCR verified the ELISA results, confirming that DSS treatment increased the levels of IFN- $\gamma$, IL- 8 and TNF- $\alpha$ compared with the CG, and that ART lowered these levels in UC rats (DG vs. CG, $\mathrm{P}<0.001$; MG vs. $\mathrm{DG}, \mathrm{P}<0.01$ or $\mathrm{P}<0.001$; HG vs. DG, $\mathrm{P}<0.001$; PG vs. DG, $\mathrm{P}<0.001$; Fig. 5B).

Protective effect of ART against RAW264.7 cell damage caused by LPS. Following treatment with LPS, used to induce inflammation, RAW264.7 cell infiltration was markedly increased. H\&E staining revealed that the cells became larger and more rounded when compared with the control cells $(\mathrm{P}<0.001)$; however, ART treatment reduced cell infiltration, and the cell shape and size were gradually restored (Fig. 6A). Therefore, ART alleviated cell injury in a dose-dependent manner, and the pathological score of LPS-treated cells was significantly higher in comparison with that of the 5-ASA, ART 5, ART 10 and ART 20 groups (ART 5 vs. LPS, P<0.05; ART 10 vs. LPS, P<0.01; ART 20 vs. LPS, $\mathrm{P}<0.001$; 5-ASA vs. LPS, P<0.001; Fig. 6B).

Effects of ART on the levels of inflammatory factors in RAW264.7 cells. ELISA demonstrated that, when compared
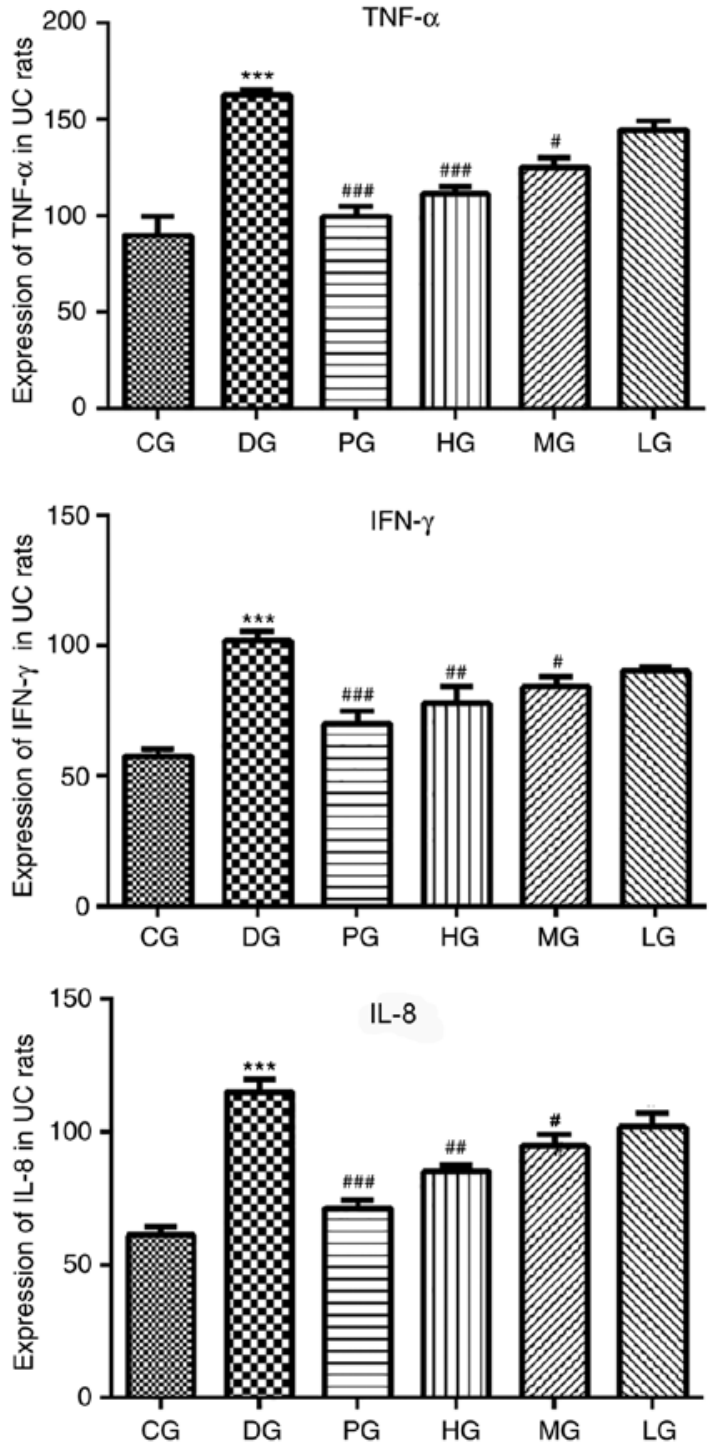

Figure 4. Effects of ART on the serum levels of inflammatory factors in ulcerative colitis rats. ELISA analysis indicated that DSS treatment increased the levels of IFN- $\gamma$, IL- 8 and TNF- $\alpha$, whereas ART exposure reversed these effects. ${ }^{* * *} \mathrm{P}<0.001$ vs. $\mathrm{CG} ;{ }^{\#} \mathrm{P}<0.05,{ }^{\# \#} \mathrm{P}<0.01$ and ${ }^{\# \# \#} \mathrm{P}<0.001$, vs. DG. ART, artesunate; IFN- $\gamma$, interferon- $\gamma$; IL, interleukin; TNF- $\alpha$, tumor necrosis factor $\alpha$; DSS, dextran sulfate sodium; CG, control group; DG, DSS-treated model group; LG, low-dose ART group; MG, middle-dose ART group; $\mathrm{HG}$, high-dose ART group; PG, positive control group. 
A
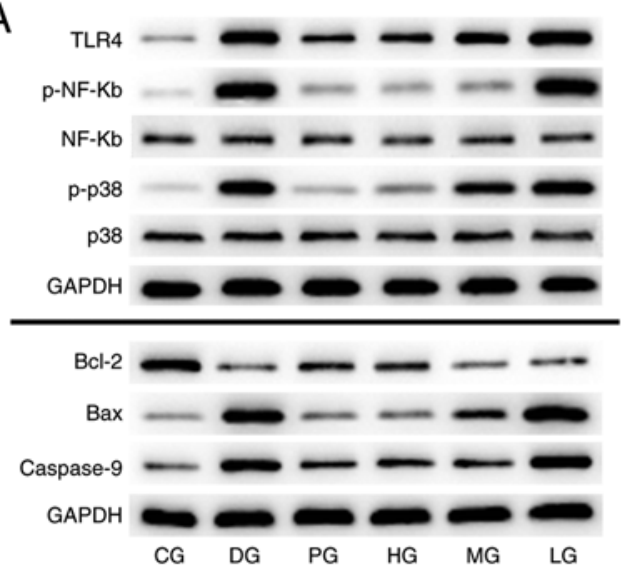
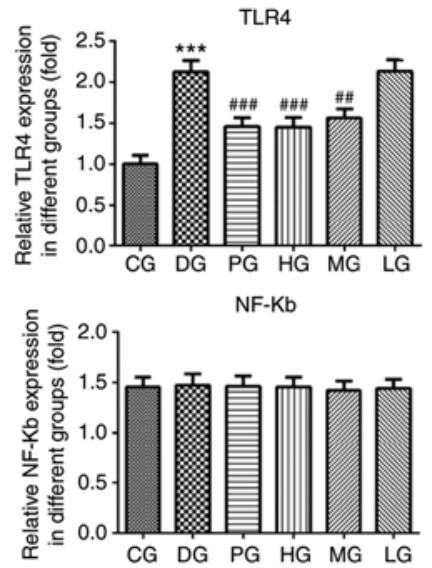
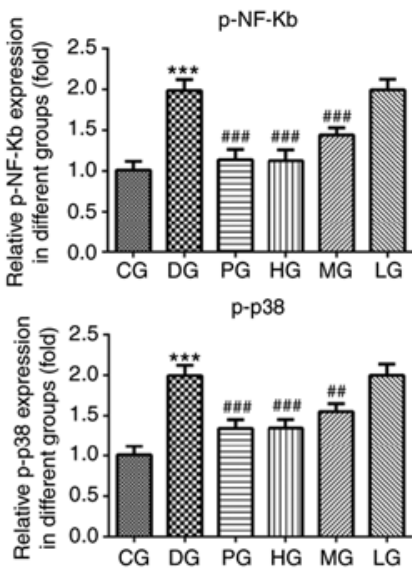
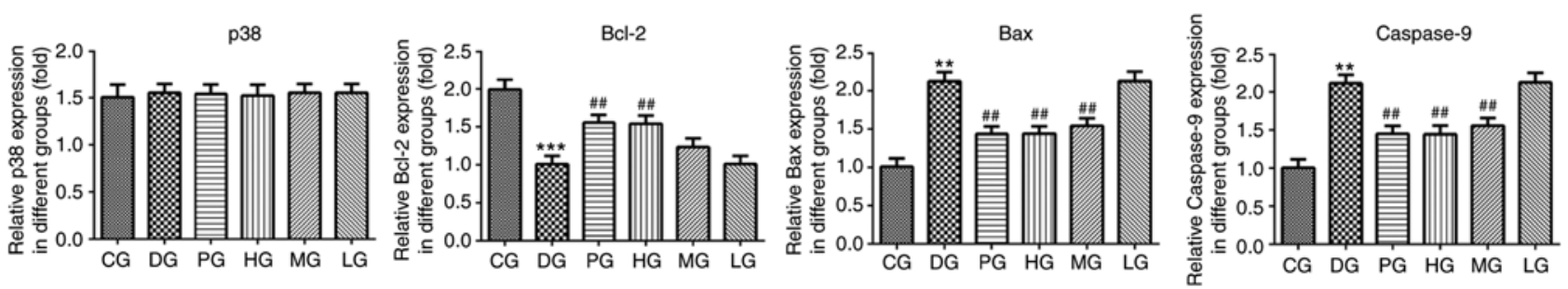

$\mathrm{B}$
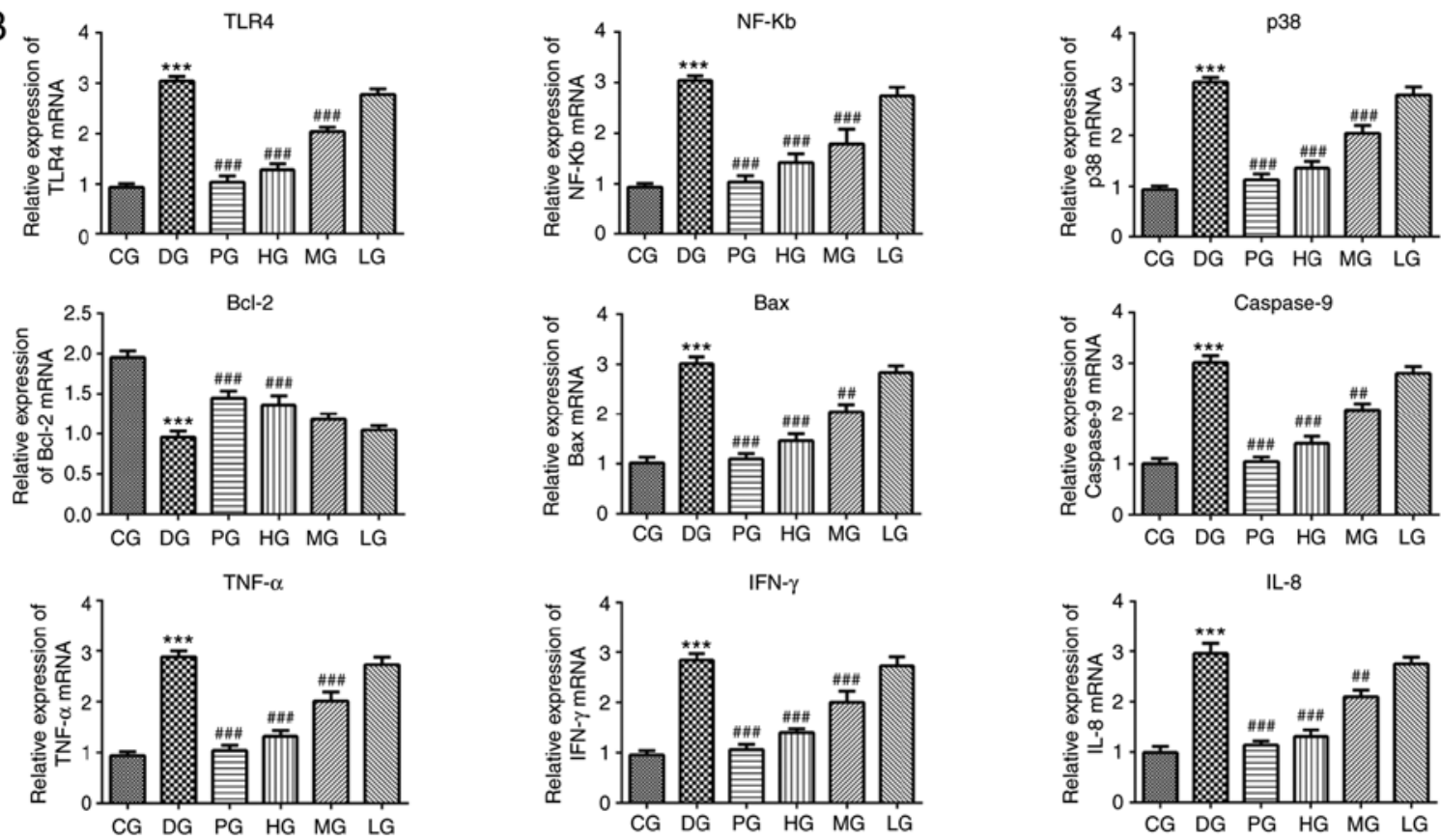

Figure 5. Effects of ART on the levels of key molecules involved in TLR4-NF-kB signaling pathway in ulcerative colitis rats. (A) Western blot analysis of the effects of ART on the levels of key molecules involved in the TLR4-NF- $\kappa$ B signaling pathway. DSS-treatment increased the protein expression levels of TLR4, p-NF- $\kappa$ B, p-p38, Bax and caspase-9, and downregulated Bcl-2, whereas ART reversed these levels. (B) Reverse transcription-quantitative polymerase chain reaction analysis yielded similar results to the protein expression observations of western blot analysis. ${ }^{* *} \mathrm{P}<0.01$ and ${ }^{* * *} \mathrm{P}<0.001$, vs. CG; ${ }^{\# \#} \mathrm{P}<0.01$ and

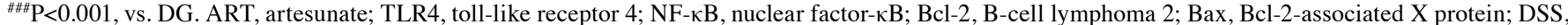
dextran sulfate sodium; CG, control group; DG, DSS-treated model group; LG, low-dose ART group; MG, middle-dose ART group; HG, high-dose ART group; PG, positive control group.

with the control cells, LPS treatment increased the levels of the inflammatory factors IFN- $\gamma$, IL- 8 and TNF- $\alpha$ in cells induced by LPS $(\mathrm{P}<0.001)$. However, ART lowered the levels of the abovementioned inflammatory factors in a dose-dependent manner. The difference in the levels between the LPS-treated group, and the 5-ASA and ART 20 groups were statistically significant for all factors, while a marked decrease in IL-8 and TNF- $\alpha$ levels was also observed in ART 10 compared with the LPS group (Fig. 7).
Effect of ART on cell viability. The results of the CCK-8 assay demonstrated that LPS treatment significantly reduced cell viability when compared with that in the control (at $48 \mathrm{~h}, \mathrm{P}<0.01$; at $72 \mathrm{~h}, \mathrm{P}<0.001)$. ART exposure improved the cell viability in a dose-dependent manner, with statistically significant differences detected between the LPS group, and the 5-ASA, ART 5, ART 10 and ART 20 groups at $72 \mathrm{~h}$ (ART 5 vs. LPS, P<0.05; ART 10 vs. LPS, P<0.01; ART 20 vs. LPS, $\mathrm{P}<0.001 ; 5$-ASA vs. LPS, $\mathrm{P}<0.001$; Fig. $8 \mathrm{~A}$ ). 
A
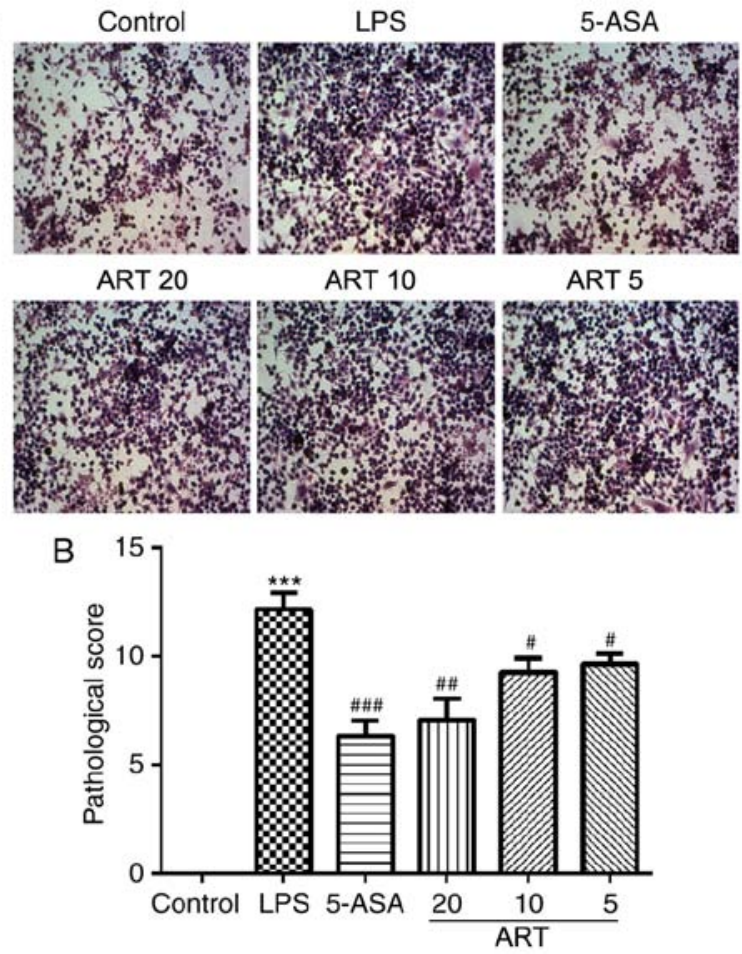

Figure 6. Effects of ART on histological changes in RAW264.7 cells. (A) Representative images of hematoxylin and eosin staining (magnification, $\mathrm{x} 200$ ), and (B) quantification of the histological score of RAW264.7 cells in each group. ${ }^{* * *} \mathrm{P}<0.001$ vs. control group; ${ }^{\#} \mathrm{P}<0.05,{ }^{\# \#} \mathrm{P}<0.01$ and

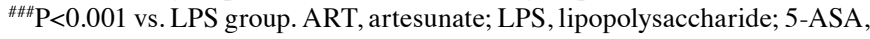
5 -aminosalicylic acid.

Effect of ART on cell migration. As shown in Fig. 8B and C, the Transwell assay revealed that LPS treatment significantly increased cell migration compared with the control cells $(\mathrm{P}<0.001)$. ART reduced cell migration in a dose-dependent manner, with statistically significant differences observed between the LPS group, and the 5-ASA, ART 5, ART 10 and ART 20 groups (ART 10 vs. LPS, P<0.01; ART 20 vs. LPS, $\mathrm{P}<0.001 ;$ 5-ASA vs. LPS, $\mathrm{P}<0.001$; Fig. 8B).

Effect of ART on the regulation of key molecules involved in the TLR4-NF- $\kappa B$ signaling pathway in RAW264.7 cells. Western blot analysis demonstrated that, when compared with the control cells, LPS treatment in RAW264.7 cells significantly increased the protein levels of TLR4, p-NF- $\mathrm{KB}$, p-p38, Bax and caspase-9, whereas it reduced the protein level of Bcl-2 $(\mathrm{P}<0.001)$. Further treatment with ART activated the TLR4-NF- $\mathrm{KB}$ signaling pathway by reducing the expression levels of TLR4, p-NF- $\kappa B$, p-p38, Bax and caspase-9, while increasing Bcl-2 expression in a dose-dependent manner. Statistically significant differences in these levels were observed between the LPS-treated group, and the 5-ASA, ART 10 and ART 20 groups (ART 10 vs. LPS, P<0.05; ART 20 vs. LPS, $\mathrm{P}<0.01$; 5-ASA vs. LPS, $\mathrm{P}<0.01$; Fig. 9).

\section{Discussion}

UC is a recurrent and prolonged inflammatory disease of the digestive system. Its pathological manifestations are diverse, including diarrhea (30), abdominal pain (25), and
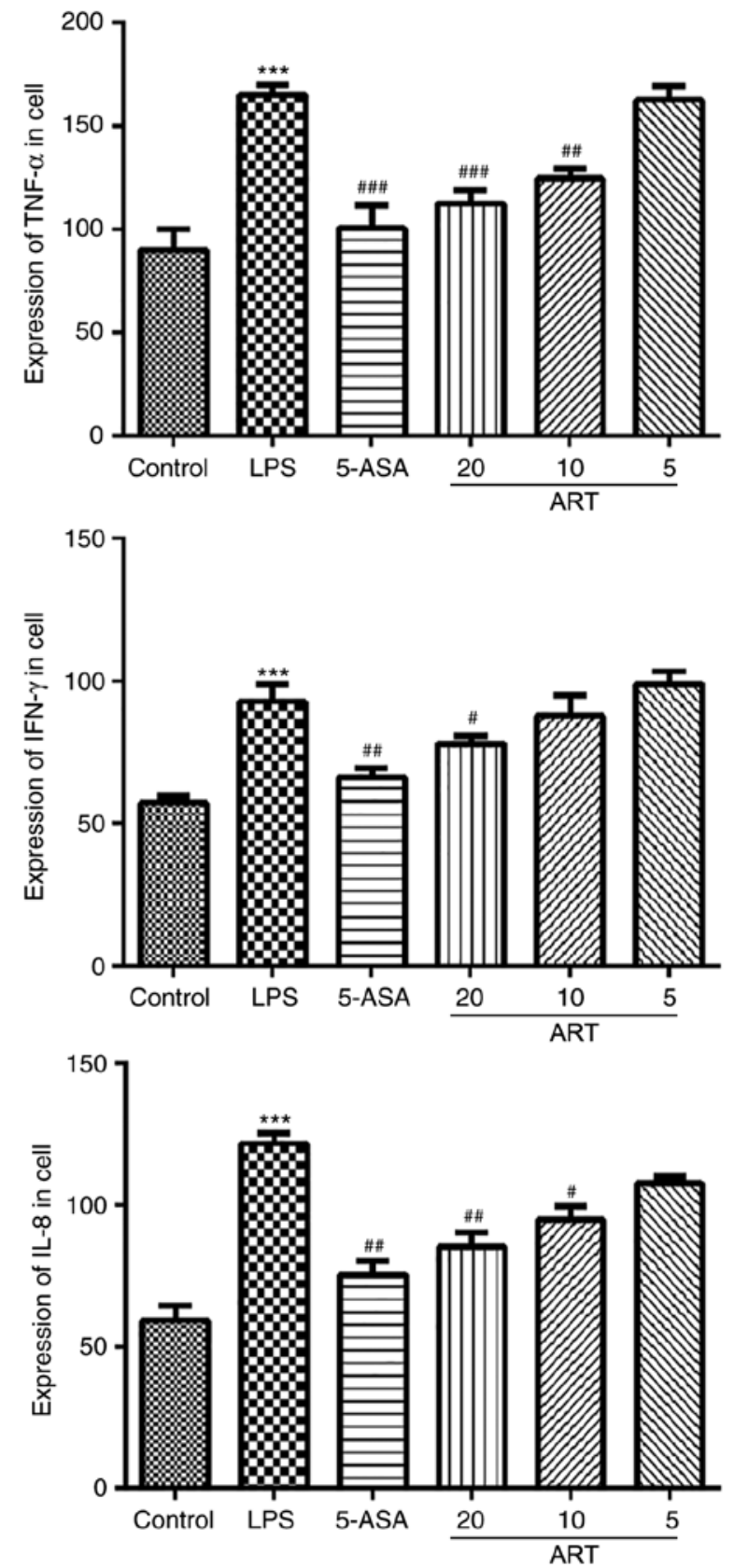

Figure 7. Effects of ART on the levels of inflammatory factors in RAW264.7 cells. ELISA revealed that LPS treatment increased the levels of IFN- $\gamma$, IL-8 and TNF- $\alpha$, whereas ART reversed these effects. ${ }^{* * * *} \mathrm{P}<0.001$ vs. control group; ${ }^{\#} \mathrm{P}<0.05,{ }^{\# \#} \mathrm{P}<0.01$ and ${ }^{\# \# \#} \mathrm{P}<0.001$, vs. LPS group. ART, artesunate; LPS, lipopolysaccharide; IFN- $\gamma$, interferon- $\gamma$; TNF- $\alpha$, tumor necrosis factor $\alpha$.

tenesmus (31), among others. Several drugs are effective in the treatment of UC; however, the majority of these are accompanied by notable side effects, which significantly inhibit their widespread clinical application. Although the aminosalicylate 5-ASA has been widely used as a first-line medicine for UC therapy, earlier findings have indicated that 5-ASA may cause symptoms of diarrhea in patients with UC (32). In addition, careful monitoring is required when 5-ASA is administered to treat UC in elderly patients with renal impairment or cardiac failure (33).

ART treatment appears to be promising in terms of tolerance in malaria patients, and the pharmacokinetics of this agent 
A

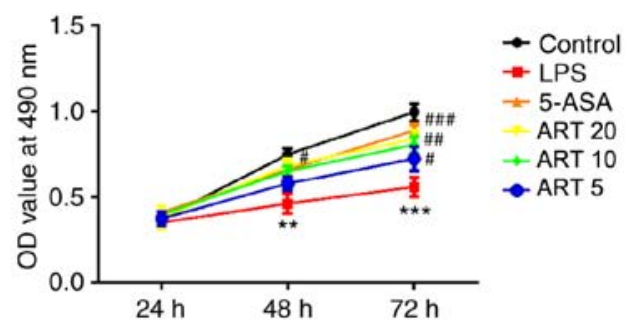

B

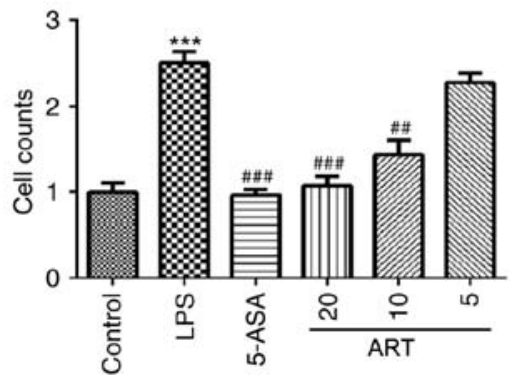

C
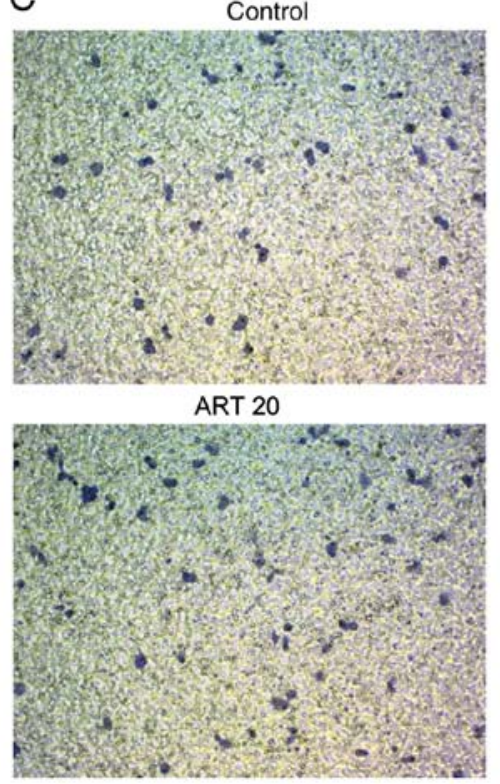
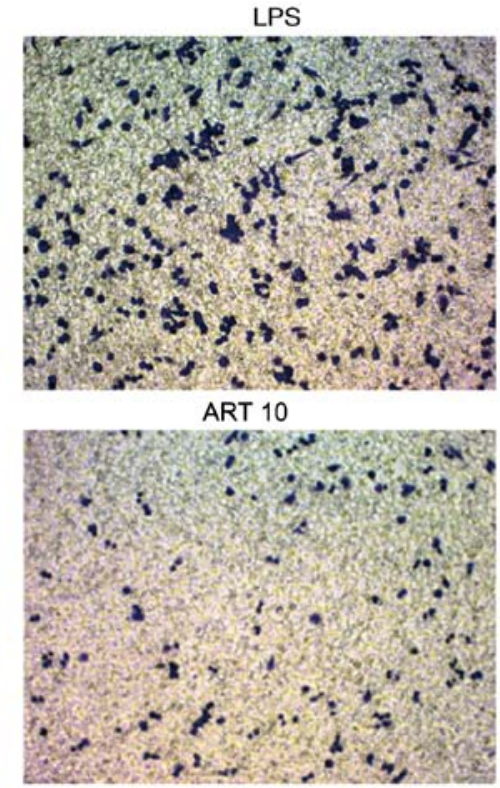

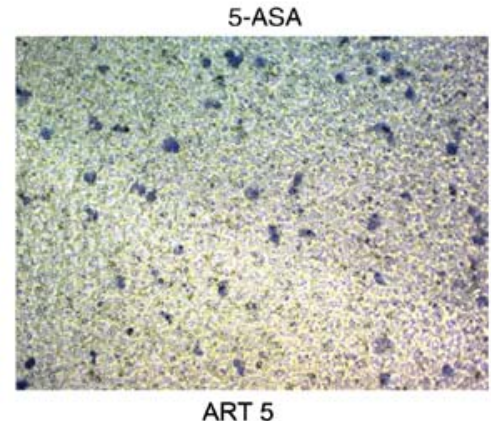

ART 5

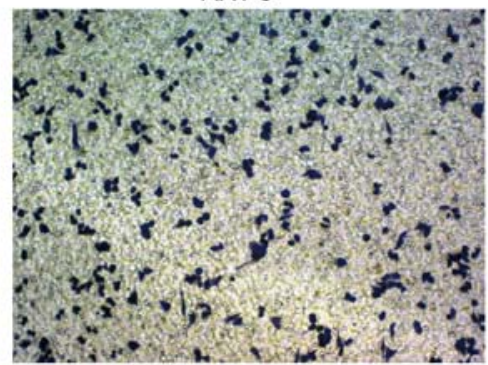

Figure 8. Effects of ART on the viability and migration abilities of RAW264.7 cells. (A) RAW264.7 cell proliferation in the LPS group was inhibited when compared with that in the control group; however, the activity of the cells was improved following ART treatment. (B) Quantified number of migrated cells in each group, and $(\mathrm{C})$ representative images of Transwell membranes (magnification, $\mathrm{x} 200$; staining, $0.05 \%$ crystal violet solution). ${ }^{* *} \mathrm{P}<0.01$ and ${ }^{* * *} \mathrm{P}<0.001$ vs. control group; ${ }^{\#} \mathrm{P}<0.05,{ }^{\# \#} \mathrm{P}<0.01$ and ${ }^{\# \# \#} \mathrm{P}<0.001$, vs. LPS group. ART, artesunate; LPS, lipopolysaccharide; 5-ASA, 5-aminosalicylic acid.

have been well-characterized (34). A recent studies further revealed that ART activation of ferroptosis is an effective, novel pathway for eliminating pancreatic ductal adenocarcinoma cells (10). In addition, previous data demonstrated that ART may reduce cell proliferation and angiogenesis, and trigger apoptosis, and that it exerts its protective effects by enhancing antioxidant activities and alleviating oxidative stress (35-37). ART is considered to be suitable for drug development due to its aqueous solubility. In the present study, it was first hypothesized that ART may attenuate the DSS-induced inflammatory damage in a UC animal model, as well as protect RAW264.7 cells against LPS-induced damage and control their inflammatory status. The results then revealed that ART reduced the DSS-induced inflammatory damage in UC rats, and protected RAW264.7 cells against LPS-induced damage and inflammatory response. To fully elucidate the mechanisms underlying the anti-inflammatory actions of ART, the present study also investigated the mechanisms mediating inflammatory damage in UC rats and the effects of ART on RAW264.7 cells.

The downstream signaling of all TLRs involves three major signaling pathways: Mitogen-activated protein kinase, IFN-regulatory factor and $\mathrm{NF}-\kappa \mathrm{B}$ signaling pathways (38). $\mathrm{NF}-\kappa \mathrm{B}$ regulates the activation and differentiation of $\mathrm{T}$ cells and inflammation (39); therefore, it was hypothesized that inactivation of the TLR4-NF- $\mathrm{B}$ signaling pathway may be important for the effective treatment of UC. LPS activates TLR4 signaling, leading to the release of TNF- $\alpha$ and IL-6, and the ensuing response to inflammation (40). Based on this mounting evidence, a genetic association between TNF- $\alpha$ and UC was predicted. In the present study, the activity of the TLR4-NF- $\kappa$ B pathway and the expression of inflammatory genes were found to be induced by DSS treatment. In addition, the extent of damage to the colon of UC rats was aggravated, as reflected by alterations in DAI, MPO, colon length and $\mathrm{Hb}$ expression. Furthermore, western blotting, RT-qPCR analysis and ELISA confirmed that ART inhibited the TLR4-mediated NF- $\kappa$ B activation, leading to decreased release of the pro-inflammatory cytokines IFN- $\gamma$, IL- 8 and TNF- $\alpha$, markedly reducing colonic damage in UC rats. The anti-inflammatory effect of ART in UC rats was similar to its role in LPS-induced RAW264.7 cells. In vitro experiments demonstrated that ART treatment attenuated the LPS-induced migration, activity and apoptosis of RAW264.7 cells, as well as the release of inflammatory mediators, as confirmed by $\mathrm{H} \& \mathrm{E}$ staining, CCK-8 assay, Transwell assay and ELISA. ART also decreased the LPS-induced expression levels of factors associated with the TLR4-NF- $\mathrm{B}$ pathway and inflammation, as determined by western blotting.

As previously reported, upregulation of Bax and caspase-3, and downregulation of $\mathrm{Bcl}-2$ may result in cell apoptosis. Bax 
A
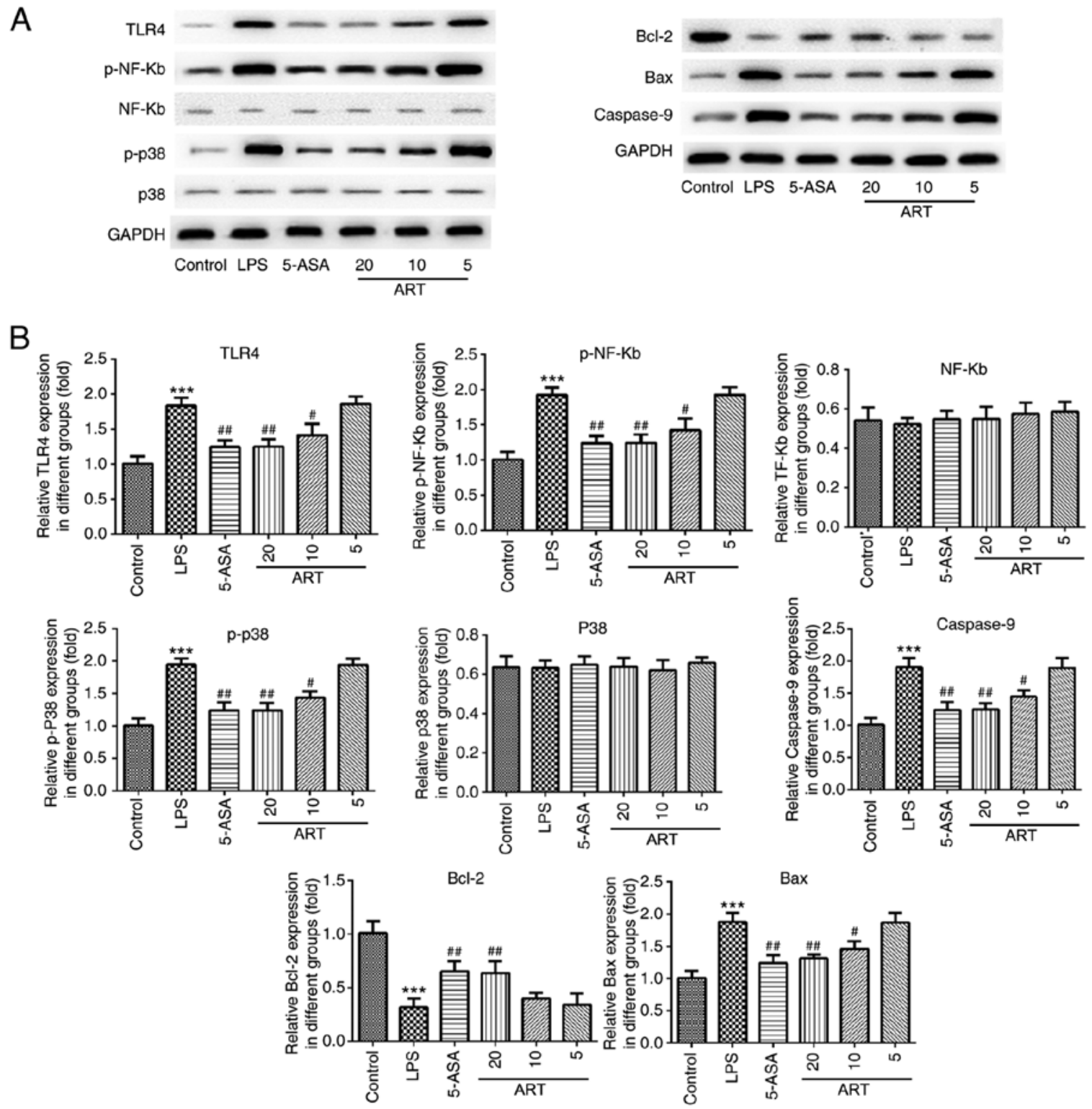

Figure 9. Effects of ART on the levels of key molecules involved in the TLR4-NF-кB signaling pathway in RAW264.7 cells. (A) Western blot analysis demonstrated the effects of ART on the levels of key molecules involved in TLR4-NF- $\mathrm{B}$ signaling. (B) LPS treatment increased the protein expression levels of TLR4, p-NF-кB, p-p38, Bax and caspase-9, and downregulated Bcl-2, whereas exposure to ART reverses these effects. No significant differences in the expression levels of $\mathrm{NF}-\kappa \mathrm{B}$ and $\mathrm{p} 38$ were reported among all groups. ${ }^{* * *} \mathrm{P}<0.001$ vs. control group; ${ }^{\#} \mathrm{P}<0.05$ and ${ }^{\# \#} \mathrm{P}<0.01$ vs. LPS group. ART, artesunate; LPS,

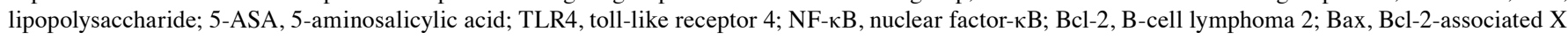
protein.

permeabilizes the mitochondrial outer membrane, releasing pro-apoptotic factors that activate caspases, and the apoptosome then activates caspase-9, which in turn leads to the activation of caspase- 3 and thus induces apoptosis $(41,42)$. In the present study, the apoptosis of colon tissue and RAW264.7 cells following intervention with ART was assessed by H\&E staining, CCK-8 assay and western blotting. Decreases in the pathological damage of colon tissue and apoptosis were observed in ART-treated DSS-induced UC rats. In addition, the migration and apoptosis of ART-treated LPS-induced RAW264.7 cells were decreased. Similarly, it was observed that ART significantly inhibited the TLR4-NF- $\mathrm{B}$ pathway and inflammatory genes in LPS-treated RAW264.7 cells. Therefore, ART appears to be beneficial in the treatment of UC by effectively reducing inflammatory damage.
However, there were certain limitations to the present study. Firstly, the properties of ART are complex, and the exact functions of this compound have not been fully elucidated. Nontprasert et al (43) reported that ART derivatives were neurotoxic to mice, and the neurotoxic effects of the artemisinin derivatives used in the treatment of several diseases have been a matter of concern over the past years. This point is reflected in the present study; for instance, the indexes of UC rats failed to return to normal levels subsequent to treatment with a high dose of ART. Compared with the positive control group, the therapeutic effect of ART is slightly inferior. In addition, following ART treatment, rats exhibited a slightly depressed mental state as compared with normal rats, which was manifested by weight loss, reduced food intake and reduced exercise time, suggesting a lack of food reward and euphoria in rats. These detection 
indexes were only used as simple daily observations in this experiment, and were not quantified or formed part of the experimental results of the present study; thus, more studies are needed to confirm this point in the future. Secondly, the present study only focused on the association between different ART dosage, and the changes of the main molecules participating in the TLR4-NF- $\kappa \mathrm{B}$ signaling pathway and inflammatory responses. Gene silencing and overexpression of TLR4-NF- $\mathrm{B}$ must be performed to study the underlying mechanism in more detail. Another limitation is that the present study only revealed the level change of caspase-9; however, theoretically the expression levels of both caspase- 3 and -9 should be examined, since numerous studies have suggested that caspase- 3 is more representative of the apoptosis pathway in comparison with caspase-9. Furthermore, a number of studies have demonstrated that various cytokines associated with UC, such as IL-1 $\beta$ and IL-6, are also able to increase inflammatory response through the TLR4-NF- $\kappa \mathrm{B}$ signaling pathway, with the exception of TNF- $\alpha$, IL- 8 and IFN- $\gamma$. Certain studies have further indicated that NF- $\mathrm{BB}$ was a key transcription factor of M1 macrophages and induced a great amount of inflammatory gene expression, including IL-1 $\beta$, IL-6, IL-10, IL-12 and cyclooxygenase-2. Thus, the relevant inflammatory factors mentioned above can be detected in further experiments. Finally, an analytical experiment with other tissues of UC rats must be conducted to investigate whether UC affects other organs as well. Therefore, in order to obtain more evidence supporting the present findings, further research is required in the future.

In conclusion, ART effectively controlled the development of UC by improving the antioxidant and anti-inflammatory status of UC rats via the TLR4-NF- $\kappa \mathrm{B}$ signaling pathway in vivo. Corresponding cell experiments in vitro demonstrated that ART affected the TLR4-NF- $\kappa \mathrm{B}$ signaling pathway by reducing cell apoptosis and the expression of inflammatory factors. The present findings are promising and support the use of ART as a natural drug with anti-inflammatory, anti-apoptotic and antioxidants properties. In view of the complex role of ART and the fact that current research on ART is limited to animal and cell experiments, further studies and clinical trials are crucial for determining whether ART may be developed into a drug for UC therapy in the future. Furthermore, the present study highlighted the importance of the TLR4-NF-kB signaling pathway in the development of UC. Inhibition of this signaling may, thus, be a possible therapeutic strategy for the treatment of UC, and ART may provide a theoretical basis for the development of new drugs for UC treatment.

\section{Acknowledgements}

The authors would like to express their deepest gratitude to the chief consultant, Dr Long-dian Chen, who has provided valuable guidance. The authors are also sincerely grateful to Prof. Yu-ling Yao, Prof. Yi-yang Zhang, Prof. Ting-sheng Ling, Prof. Ming Zhang, Dr Chun-yan Peng, Dr Gui-fang Xu and Dr Min Chen (all Nanjing Drum Tower Hospital) for their help in experimental techniques and theoretical guidance.

\section{Funding}

No funding was received.

\section{Authors' contributions}

YXC and XPZ conceived and designed the experiments, and wrote the paper. YXC, XQZ and CGY performed the experiments. SLH, YX, XTD and WJL analyzed the data. XPZ and $\mathrm{XQZ}$ provided the reagents, materials and analysis tools.

\section{Availability of data and materials}

All data generated or analyzed during the present study are included in this published article.

\section{Ethics approval and consent to participate}

All animals received humane care, and the experimental procedures were conducted in strict accordance with the health and care guidelines for experimental animals. All experimental procedures performed on the rats were approved by the Animal Experiment Ethics Committee of Nanjing Drum Tower Hospital (Nanjing, China).

\section{Patient consent for publication}

Not applicable.

\section{Competing interests}

The authors declare that they have no competing interests.

\section{References}

1. Ito A, Omori T, Hanafusa N, Tsuchiya K, Nakamura S and Tokushige K: Efficacy and safety of granulocyte adsorption apheresis in elderly patients with ulcerative colitis. J Clin Apher 33: 514-520, 2018.

2. Høivik ML, Moum B, Solberg IC, Henriksen M, Cvancarova M and Bernklev T; IBSEN Group: Work disability in inflammatory bowel disease patients 10 years after disease onset: Results from the IBSEN Study. Gut 62: 368-375, 2013.

3. Torres J, Billioud V, Sachar DB, Peyrin-Biroulet L and Colombel JF: Ulcerative colitis as a progressive disease: The forgotten evidence. Inflamm Bowel Dis 18: 1356-1363, 2012.

4. Ungaro R, Mehandru S, Allen PB, Peyrin-Biroulet L and Colombel JF: Ulcerative colitis. Lancet 389: 1756-1770, 2017.

5. Tsuda K, Miyamoto L, Hamano S, Morimoto Y, Kangawa Y, Fukue C, Kagawa Y, Horinouchi Y, Xu W, Ikeda Y, et al: Mechanisms of the $\mathrm{pH}$ - and oxygen-dependent oxidation activities of artesunate. Biol Pharm Bull 41: 555-563, 2018.

6. Efferth T, Giaisi M, Merling A, Krammer PH and Li-Weber M: Artesunate induces ROS-mediated apoptosis in doxorubicin-resistant T leukemia cells. PLoS One 2: e693, 2007.

7. Ooko E, Saeed ME, Kadioglu O, Sarvi S, Colak M, Elmasaoudi K, Janah R, Greten HJ and Efferth T: Artemisinin derivatives induce iron-dependent cell death (ferroptosis) in tumor cells. Phytomedicine 22: 1045-1054, 2015.

8. Button RW, Lin F, Ercolano E, Vincent JH, Hu B, Hanemann CO and Luo S: Artesunate induces necrotic cell death in schwannoma cells. Cell Death Dis 5: e1466, 2014.

9. Berdelle N, Nikolova T, Quiros S, Efferth T and Kaina B: Artesunate induces oxidative DNA damage, sustained DNA double-strand breaks, and the ATM/ATR damage response in cancer cells. Mol Cancer Ther 10: 2224-2233, 2011.

10. Eling N, Reuter L, Hazin J, Hamacher-Brady A and Brady NR: Identification of artesunate as a specific activator of ferroptosis in pancreatic cancer cells. Oncoscience 2: 517-532, 2015.

11. Cen Y, Liu C, Li X, Yan Z, Kuang M, Su Y, Pan X, Qin R, Liu X, Zheng J and Zhou H: Artesunate ameliorates severe acute pancreatitis (SAP) in rats by inhibiting expression of pro-inflammatory cytokines and Toll-like receptor 4. Int Immunopharmacol 38: 252-260, 2016 
12. Sands BE and Kaplan GG: The role of TNFalpha in ulcerative colitis. J Clin Pharmacol 47: 930-941, 2007.

13. Allocca M, Furfaro F, Fiorino G, Gilardi D, D'Alessio S and Danese S: Can IL-23 be a good target for ulcerative colitis? Best Pract Res Clin Gastroenterol 32-33: 95-102, 2018.

14. Jeoung BR, Lee KD, Na CS, Kim YE, Kim B and Kim YR Ganghwaljetongyeum, an anti-arthritic remedy, attenuates synoviocyte proliferation and reduces the production of proinflammatory mediators in macrophages: The therapeutic effect of GHJTY on rheumatoid arthritis. BMC Complement Altern Med 13: 47, 2013.

15. Jeong HY, Choi YS, Lee JK, Lee BJ, Kim WK and Kang H: Anti-inflammatory activity of citric acid-treated wheat germ extract in lipopolysaccharide-stimulated macrophages. Nutrients 9, 2017.

16. Xiang Y, Ye W, Huang C, Lou B, Zhang J, Yu D, Huang X, Chen B and Zhou M: Brusatol inhibits growth and induces apoptosis in pancreatic cancer cells via JNK/p38 MAPK/NF-kb/Stat3/Bcl-2 signaling pathway. Biochem Biophys Res Commun 487: 820-826, 2017.

17. Xie Z, Xiao Z and Wang F: Hepatitis $C$ virus nonstructural $5 \mathrm{~A}$ protein (HCV-NS5A) inhibits hepatocyte apoptosis through the NF-kb/miR-503/bcl-2 pathway. Mol Cells 40: 202-210, 2017.

18. Eissa N, Hussein H, Kermarrec L, Elgazzar O, Metz-Boutigue MH, Bernstein $\mathrm{CN}$ and Ghia JE: Chromofungin (CHR: $\left.\mathrm{CHGA}_{47-66}\right)$ is downregulated in persons with active ulcerative colitis and suppresses pro-inflammatory macrophage function through the inhibition of NF-kB signaling. Biochem Pharmacol 145: 102-113, 2017.

19. Gu P, Zhu L, Liu Y, Zhang L, Liu J and Shen H: Protective effects of paeoniflorin on TNBS-induced ulcerative colitis through inhibiting NF-kappaB pathway and apoptosis in mice. Int Immunopharmacol 50: 152-160, 2017.

20. Ding X, Liang Y, Peng W, Li R, Lin H, Zhang Y and Lu D: Intracellular TLR22 acts as an inflammation equalizer via suppression of NF- $\kappa \mathrm{B}$ and selective activation of MAPK pathway in fish. Fish Shellfish Immunol 72: 646-657, 2018

21. Pan T, Shi X, Chen H, Chen R, Wu D, Lin Z, Zhang J and Pan J: Geniposide suppresses interleukin-1 $\beta$-induced inflammation and apoptosis in rat chondrocytes via the PI3K/Akt/NF- $\kappa \mathrm{B}$ signaling pathway. Inflammation 41: 390-399, 2018

22. Liu B, Li S, Sui X, Guo L, Liu X, Li H, Gao L, Cai S, Li Y, Wang $\mathrm{T}$ and Piao $\mathrm{X}$ : Root extract of polygonum cuspidatum Siebold \& Zucc. ameliorates DSS-induced ulcerative colitis by affecting NF-kappaB signaling pathway in a mouse model via synergistic effects of polydatin, resveratrol, and emodin. Front Pharmacol 9: 347, 2018

23. Manolakis AC, Kapsoritakis AN, Kapsoritaki A, Tiaka EK, Oikonomou KA, Lotis V, Vamvakopoulou D, Davidi I, Vamvakopoulos N and Potamianos SP: Readressing the role of toll-like receptor-4 alleles in inflammatory bowel disease: Colitis, smoking, and seroreactivity. Dig Dis Sci 58: 371-380, 2013.

24. Liu Y, Zhang Z, Wang L, Li J, Dong L, Yue W, Chen J, Sun X, Zhong L and Sun D: TLR4 monoclonal antibody blockade suppresses dextran-sulfate-sodium-induced colitis in mice. J Gastroenterol Hepatol 25: 209-214, 2010.

25. Castelli AA, Estrada JJ and Kaminski JP: Patient with ulcerative colitis and abdominal pain. JAMA Surg 153: 282-283, 2018.

26. Murthy SN, Cooper HS, Shim H, Shah RS, Ibrahim SA and Sedergran DJ: Treatment of dextran sulfate sodium-induced murine colitis by intracolonic cyclosporin. Dig Dis Sci 38: 1722-1734, 1993.

27. Cooper HS, Murthy SN, Shah RS and Sedergran DJ: Clinicopathologic study of dextran sulfate sodium experimental murine colitis. Lab Invest 69: 238-249, 1993.
28. Yang YH, Li DL, Bi XY, Sun L, Yu XJ, Fang HL, Miao Y, Zhao M, He X, Liu JJ and Zang WJ: Acetylcholine inhibits LPS-induced MMP-9 production and cell migration via the $\alpha 7$ nAChR-JAK2/STAT3 pathway in RAW264.7 cells. Cell Physiol Biochem 36: 2025-2038, 2015.

29. Livak KJ and Schmittgen TD: Analysis of relative gene expression data using real-time quantitative PCR and the 2(-Delta Delta C(T)) method. Methods 25: 402-408, 2001

30. Zhong W, Lu X, Shi H, Zhao G, Song Y, Wang Y, Zhang J, Jin $Y$ and Wang S: Distinct microbial populations exist in the mucosa-associated microbiota of diarrhea predominant irritable bowel syndrome and ulcerative colitis. J Clin Gastroenterol: 28 Nov, 2017 doi: 10.1097/MCG.0000000000000961 (Epub ahead of print).

31. Nigg, Kolyvanos N, Käser, Vetter. Colitis ulcerosa. Praxis. 97 : 167-174, 2008.

32. Shimodate Y, Takanashi K, Waga E, Fujita T, Katsuki S and Nomura M: Exacerbation of bloody diarrhea as a side effect of mesalamine treatment of active ulcerative colitis. Case Rep Gastroenterol 5: 159-165, 2011.

33. Muller AF, Stevens PE, McIntyre AS, Ellison H and Logan RF: Experience of 5-aminosalicylate nephrotoxicity in the United Kingdom. Aliment Pharmacol Ther 21: 1217-1224, 2005

34. Ericsson T, Blank A, von Hagens C, Ashton M and Äbelö A: Population pharmacokinetics of artesunate and dihydroartemisinin during long-term oral administration of artesunate to patients with metastatic breast cancer. Eur J Clin Pharmacol 70: 1453-1463, 2014.

35. Anfosso L, Efferth T, Albini A and Pfeffer U: Microarray expression profiles of angiogenesis-related genes predict tumor cell response to artemisinins. Pharmacogenomics J 6: 269-278, 2006

36. Efferth T, Sauerbrey A, Olbrich A, Gebhart E, Rauch P, Weber HO, Hengstler JG, Halatsch ME, Volm M, Tew KD, et al: Molecular modes of action of artesunate in tumor cell lines. Mol Pharmacol 64: 382-394, 2003.

37. Efferth T, Ramirez T, Gebhart E and Halatsch ME: Combination treatment of glioblastoma multiforme cell lines with the anti-malarial artesunate and the epidermal growth factor receptor tyrosine kinase inhibitor OSI-774. Biochem Pharmacol 67: $1689-1700,2004$

38. Kumar H, Kawai T and Akira S: Toll-like receptors and innate immunity. Biochem Biophys Res Commun 388: 621-625, 2009.

39. Chi W, Chen H, Li F, Zhu Y, Yin W and Zhuo Y: HMGB1 promotes the activation of NLRP3 and caspase- 8 inflammasomes via NF- $\kappa \mathrm{B}$ pathway in acute glaucoma. J Neuroinflammation 12: 137, 2015.

40. Saluk J, Bijak M, Posmyk M and Zbikowska H: Red cabbage anthocyanins as inhibitors of lipopolysaccharide-induced oxidative stress in blood platelets. Int J Biol Macromol 80: 702-709, 2015.

41. Martinou JC and Green DR: Breaking the mitochondrial barrier. Nat Rev Mol Cell Biol 2: 63-67, 2001.

42. Siddiqui WA, Ahad A and Ahsan H: The mystery of BCL2 family: Bcl-2 proteins and apoptosis: An update. Arch Toxicol 89: 289-317, 2015.

43. Nontprasert A, Pukrittayakamee S, Dondorp AM, Clemens R, Looareesuwan S and White NJ: Neuropathologic toxicity of artemisinin derivatives in a mouse model. Am J Trop Med Hyg 67: 423-429, 2002.

This work is licensed under a Creative Commons Attribution-NonCommercial-NoDerivatives 4.0 International (CC BY-NC-ND 4.0) License. 